\title{
Structural performance of notch damaged steel beams repaired with composite materials
}

\author{
Boshra El-Taly ${ }^{1}$
}

Received: 22 November 2015/Accepted: 1 February 2016/Published online: 9 March 2016

(C) The Author(s) 2016. This article is published with open access at Springerlink.com

\begin{abstract}
An experimental program and an analytical model using ANSYS program were employed to estimate the structural performance of repaired damaged steel beams using fiber reinforced polymer (FRP) composite materials. The beams were artificially notched in the tension flanges at mid-spans and retrofitted by FRP flexible sheets on the tension flanges and the sheets were extended to cover parts of the beams webs with different heights. Eleven box steel beams, including one intact beam, one notch damaged beam and nine notches damaged beam and retrofitted with composite materials, were tested in twopoint loading up to failure. The parameters considered were the FRP type (GFRP and CFRP) and number of layers. The results indicated that bonding CFRP sheets to both of the tension steel flange and part of the webs, instead of the tension flange only, enhances the ultimate load of the retrofitted beams, avoids the occurrence of the debonding and increases the beam ductility. Also the numerical models give acceptable results in comparison with the experimental results.
\end{abstract}

Keywords Box steel beam - Composite materials . Retrofit methods · Finite element analysis · Non-linear analysis

Boshra El-Taly

boushra_eltaly@yahoo.com

1 Lecturer in Civil Engineering Department, Faculty of Engineering, Minoufia University, Shibin Al Kawm, Egypt

\section{Introduction}

FRP composite materials were initially used as strengthening materials for reinforced concrete (RC) flexural components then their applications have been expanded to wood, masonry, steel and concrete-steel composite structures. The composite materials may be glass or carbon-FRP materials (GFRP or CFRP) and they are used in the form of flexible sheets or rigid plates. They have light weight, high tension strength and high resistance to corrosion. FRP is fixed in the structure by adhesive (resin) material. The bond at the interface between the structure and FRP controls in the transferring force between them. The researches effort in the field of retrofitting steel I beam by bonding CFRP plate into the beam lower flange showed that the presence of the CFRP plate can help to increase the ultimate strength and post-elastic stiffness of typical I-steel beams (especially when a high modulus CFRP is used). Also various failure modes occurred for such FRP-plated steel beams; plate end debonding in an FRP-plated steel beam is the basic mode of failure. This because high interfacial shear stresses and peeling stresses localize in the vicinity of the plate end. Plate end debonding can be delayed by increasing the bonded length (Schnerch et al. 2007; Tavakkolizadeh and Saadatmanesh 2003; Photiou et al. 2006a, b; Michael et al. 2005; Gu et al. 2012; Jesus et al. 2012; Buyukozturk and Hearing 1999; Shaat and Fam 2006, 2009; Teng et al. 2012; Salama and Abd-El-Meguid 2010; Yu et al. 2011; Hmidan et al. 2013; Ochi et al. 2011; Kalavagunta et al. 2014).

Various researches examined the feasibility and effectiveness of rehabilitation of deteriorated steel structures using FRP materials. Deterioration in steel structures occurs due to excessive service load, fatigue damage or environmental contribution (corrosion). The researches 
efforts in this field generally focused on repairing naturally deteriorated steel structure elements or repairing artificially damaged steel structure elements. In 1996, two I-girders were removed from an old and deteriorated bridge. The two girders had uniform corrosion along their length and this corrosion mostly concentrated within the tension flange and the webs of the girders were not severely corroded. This corrosion caused approximately, a $40 \%$ loss of the tension flange. The two beams were repaired along the entire length of the girders using a single layer of CFRP strip with $6.4 \mathrm{~mm}$ thick then they were tested. The results indicated that the elastic stiffness of the first and second girders increased by 10 and $37 \%$, respectively. The ultimate capacities of the first and second girders were also increased by 17 and $25 \%$, respectively (Gillespie et al. 1996)

On the other hand various researches studied the structural performance of repairing artificially damaged composite or non-composite steel beam using FRP element. Section loss due to corrosion has been simulated artificially by cutting part of the flange or the web, or machining the tension flange to a reduced thickness throughout the entire span. Fatigue cracks have been simulated by introducing partial or complete saw cut in the steel flange thickness. Another method of introducing an artificial damage is by loading the steel girder beyond yielding and then unloading. Liu et al. (2001) studied the effect of repairing damaged non-composite I-beams using HM-CFRP plate. The tension flange of the damaged beams was completely cut. Their results indicated that the repaired specimens did not recover the total strength of the control intact specimen. The failure mode of specimen with full length repair was due to a gradual debonding of the CFRP laminate which initiated at mid-span and extended to the end as the load increased. Tavakkolizadeh and Saadatmanesh (2003) and (Al-Saidy et al. 2004) examined the effect of repairing partial cutting of the tension flange of composite beams using SM-CFRP sheets and HM-CFRP plates, respectively. Tavakkolizadeh and Saadatmanesh (2003) indicated that the repaired specimens did not recover the total strength of the intact specimen. Also their results showed that the girder having $25 \%$ loss in tension flange failed by rupture of CFRP. On the other hand the girder having $50 \%$ loss in tension flange failed by crushing of the concrete slab, followed by a limited debonding of the CFRP laminate at mid-span. In the case of the girder having $100 \%$ loss in tension flange complete debonding of CFRP laminate occurred. Al-Saidy et al. (2004) showed that repairing the girders using HM-CFRP plates was able to fully restore the strength of the original undamaged girders. The CFRP debonding mode of failure was not observed in their study and only crushing of the concrete slab or rupture of the CFRP plates was reported. Shaat (2007) studied the effect of repairing the damage composite steel beams by bonding SM-CFRP or HM-CFRP sheets on the bottom side of the tension steel flange and on both the bottom and top sides of the tension flange. The steel tension flanges were completely cut at mid-span to represent a severe section loss in bridge girders. His results indicated that bonding SMCFRP sheets to both sides of the steel flange enhances flexural stiffness of the repaired girders, but has no effect on flexural strength.

Eleven box steel beams (one control intact beam, one artificially damaged beam and nine artificially damaged beams and repaired with FRP composite material) were tested in four-point bending configuration. The tension flange is saw-cut at mid-span to simulate section loss due to a fatigue crack or a localized severe corrosion. FRP material is then adhesively bonded to the tension flange or to the tension flange and parts of the webs in order to recover and possibly exceed the original strength. Analytical models using ANSYS program were employed, verified, and used in a parametric study. The current results indicate that the FE simulations give acceptable results in comparison with the experimental results.

\section{Experimental program}

Eleven steel box beams were tested in two-point loading. All beams are of length $1000 \mathrm{~mm}$ and they have box cross section with $50 \times 50 \mathrm{~mm}$ and with $3 \mathrm{~mm}$ thickness. A schematic diagram of the typical beam (CB) and the locations of strain and dial gages are shown in Fig. 1. The specimens were categorized into four groups. The first group (Set 1) is the control specimens and it includes the control intact beam (CB) and the damaged beam (DB). The second group (Set 2) contains four artificially damaged beams and then they were repaired with FRP composite material. In this group, the damaged beams were repaired by externally bonded the composite material on the tension flange only (repaired method Case \# 1) as shown in Fig. 2. The type of FRP; glass fiber or carbon fiber and the number of layers are the parameters. In the third group (Set 3), the specimens were retrofitted by attaching the composite material in the tension-side flanges and the FRP flexible sheets were wrapped around the beams web to cover parts of them with $\mathrm{H}$ height as shown in Fig. 2. The fourth group (Set 4) included one retrofitted beam. This beam was repaired by attaching two layers of CFRP sheets on the lower tension flange and applied four GFRP strips with $20 \mathrm{~mm}$ width at the CFRP ends. These strips were wrapped around the whole section of the beam as shown in Fig. 3. In all the damaged specimens, the tension flange is saw-cut at mid-span to simulate section loss due to a fatigue crack or a localized severe corrosion. The width and depth of the 
Fig. 1 Beam details, strain and dial gage locations and notch details

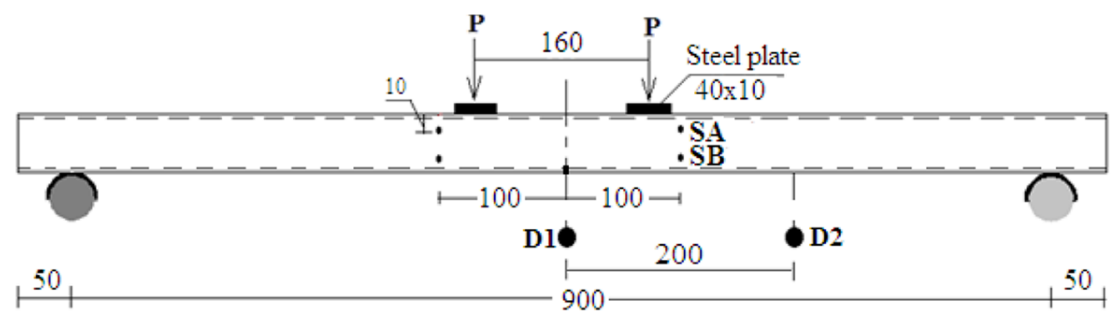

(a) Beam details, applied load, strain and dial gage locations (all dimensions in $\mathrm{mm}$ )

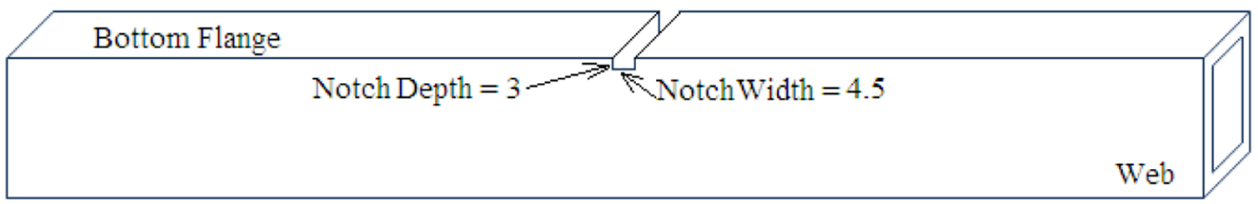

(b) Notch details

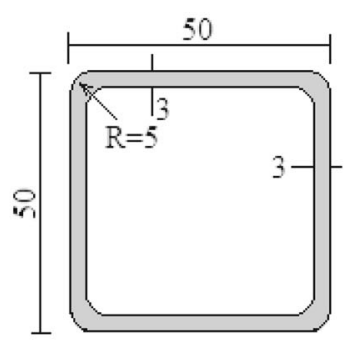

Typical cross section

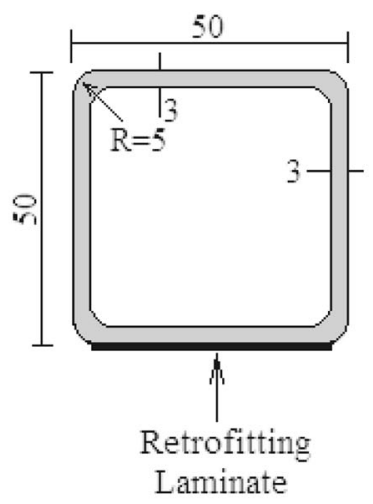

Repairing method (Case \# 1)

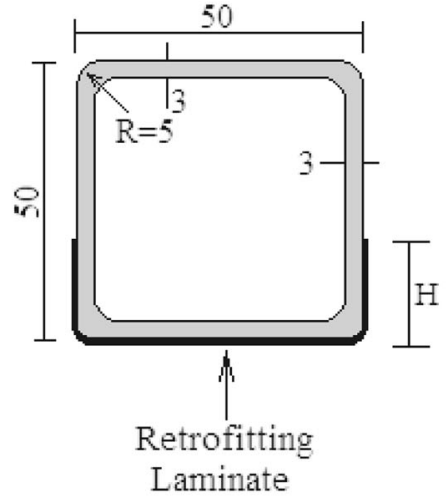

Repairing method (Case \# 2)

Fig. 2 Cross section details and method of retrofitting (all dimensions in $\mathrm{mm}$ )

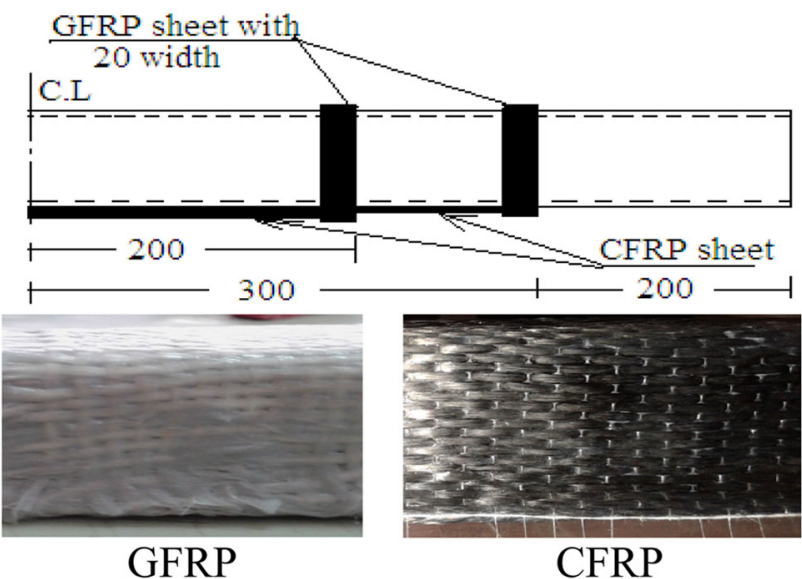

Fig. 3 Details of RB9 specimen

notch were controlled to be 4.5 and $3 \mathrm{~mm}$, respectively in all the damaged specimens. Details of the test specimens are summarized in Table 1.

The glass fiber used is a unidirectional woven glass fiber fabric with $0.172 \mathrm{~mm}$ thickness and the CFR is SikaWrap ${ }^{\circledR}$ -
$230 \mathrm{C}$ that is a unidirectional woven carbon fiber fabric for the dry application process. Its thickness is $0.131 \mathrm{~mm}$. Sikadur $^{\circledR}-330$ supplied by Sika Company was used to get sufficient bonding between steel beam and both of carbon fibre and glass fiber. It is a two parts (A and B). Part A is a resin (white) and the second part is a hardener (gray). The mixing ratio was $4: 1$ (A: $\mathrm{B}$ ) by weight. Before applying the strengthened materials, the surface was clean from any dust by manual sandblasting. Table 2 shows the material properties of the CFRP, GFRP, steel and adhesive material.

The specimens were simply supported with a span of $900 \mathrm{~mm}$ between the two supports and tested under twopoint bending static loading using flexural testing machine of $100 \mathrm{kN}$ capacity. The spacing between the two concentrated point loads was $160 \mathrm{~mm}$ (see Fig. 1). The beams were tested under an increasing load up to failure at $1 \mathrm{kN}$ a constant loading rate. The behavior of beams was monitored by measuring the deflection at mid-span and at $200 \mathrm{~mm}$ distance from the mid-span using two dial gauges with an accuracy of $0.01 \mathrm{~mm}$. A set of four DEMEC strain gauges were fixed in one side of the specimen to allow 
Table 1 Specimens details

\begin{tabular}{|c|c|c|c|}
\hline Group I.D. & Specimens I.D. & Beam designation & Retrofitting configuration \\
\hline \multirow[t]{2}{*}{ Set 1} & $\mathrm{CB}$ & Intact & None \\
\hline & DB & Damaged & None \\
\hline \multirow[t]{4}{*}{ Set 2} & RB1 & Repaired method Case \# 1 & 2 layer of GFRP, $600 \mathrm{~mm}$ long \\
\hline & RB2 & & 1 layer of CFRP, $600 \mathrm{~mm}$ long \\
\hline & RB3 & & 1 layer of CFRP, $600 \mathrm{~mm}$ long +1 layer of CFRP, $400 \mathrm{~mm}$ long \\
\hline & RB4 & & 2 layer of GFRP, $600 \mathrm{~mm}$ long +2 layer of GFRP, $400 \mathrm{~mm}$ long \\
\hline \multirow[t]{4}{*}{ Set 3} & RB5 & Repaired method Case \# 2 & 2 layer of GFRP, $600 \mathrm{~mm}$ long (web height $(\mathrm{H})=10 \mathrm{~mm}$ ) \\
\hline & RB6 & & 1 layer of CFRP, $600 \mathrm{~mm}$ long (web height $(\mathrm{H})=5 \mathrm{~mm}$ ) \\
\hline & REP7 & & $\begin{array}{l}2 \text { layer of GFRP, } 600 \mathrm{~mm} \text { long }+2 \text { layer of GFRP, } 400 \mathrm{~mm} \text { long (web } \\
\text { height }(\mathrm{H})=15 \mathrm{~mm} \text { ) }\end{array}$ \\
\hline & RB8 & & $\begin{array}{l}1 \text { layer of CFRP, } 600 \mathrm{~mm} \text { long }+1 \text { layer of CFRP, } 400 \mathrm{~mm} \text { long (web } \\
\text { height }(\mathrm{H})=15 \mathrm{~mm} \text { ) }\end{array}$ \\
\hline Set 4 & RB9 & Repaired method Case \# 1 & $\begin{array}{l}1 \text { layer of CFRP, } 600 \mathrm{~mm} \text { long }+1 \text { layer of CFRP, } 400 \mathrm{~mm} \\
\text { long + GFRP strips at the ends of CFRP }\end{array}$ \\
\hline
\end{tabular}

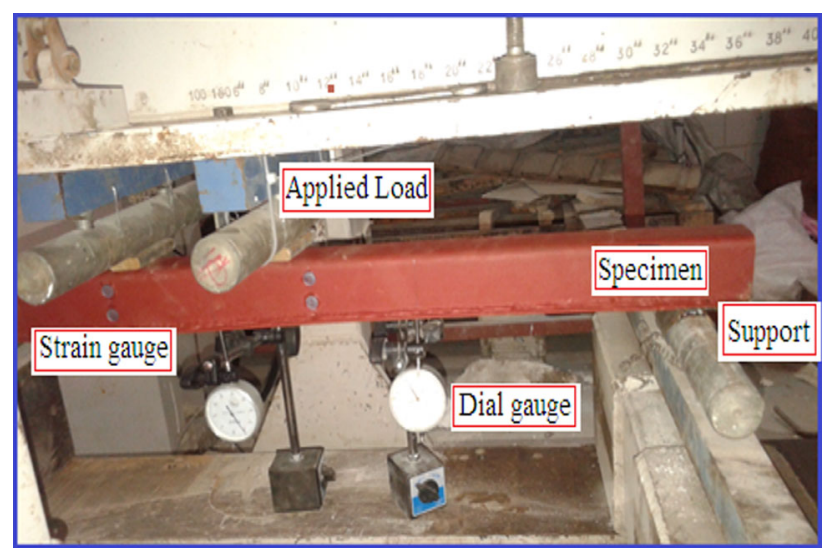

Fig. 4 Specimen test

measuring the strain versus load during the test. Typical test set-up and instrumentation is shown in Fig. 4.

\section{FE simulation}

Three dimensional models were employed to simulate the tested steel beams numerically up to failure using the general purpose Finite Element (FE) analysis program, ANSYS. Geometric and material nonlinearities were both considered into account in simulating the flexural behaviors of the retrofitted and non-retrofitted beams. Solid 185 elements (refer to ANSYS (Narmashiri and Jumaat 2011) and Narmashiri and Jumaat (ANSYS 2009)) were used to simulate the steel beams and the strengthening composite materials and the adhesive material. Each element is defined by eight nodes. Each node has three degrees of freedom at each node: translations in the nodal $x, y$, and $z$ directions. The element has plasticity, creep, swelling, stress stiffening, large deflection, and large strain capabilities. The modeling included beams having a hinged support on one side and a roller support at the other side, with a span length of $900 \mathrm{~mm}$ as per the experimental setup. The FE simulation of the control beam as example is presented in Fig. 5. The material nonlinearity was represented by multi-linear kinematic hardening constants (MKIN). It assumes that the total stress range is equal to twice the yield stresses, so that Bauschinger effect is included. MKIN may be used for materials that obey von Mises yield criteria. The material behavior was described by a stress-strain curve as presented in the experimental work. It starts at the origin and it is with positive stress and strain values. The initial slope of the curve represents the elastic modulus of the material. In the current analysis, load-control technique is used. In this technique, total load is applied to a finite element model. The load is divided into a series of load increments (load steps) during the
Table 2 Material properties of steel and composite materials

\begin{tabular}{|c|c|c|c|c|c|c|}
\hline & \multirow[t]{2}{*}{ Density $\mathrm{g} / \mathrm{cm}^{3}$} & \multirow[t]{2}{*}{ E-Modulus (Gpa) } & \multicolumn{2}{|c|}{ Tensile strength (Mpa) } & \multicolumn{2}{|l|}{ Strain } \\
\hline & & & Yield & Ultimate & Yield & Ultimate \\
\hline Steel & 7.8 & 200 & 250 & 370 & 0.00125 & 0.0135 \\
\hline CFRP & 1.76 & 238 & 4300 & - & 0.018 & - \\
\hline GFRP & 2.56 & 18.3 & 381 & - & 0.0208 & - \\
\hline Adhesive & & 3.8 & 4500 & - & 0.009 & \\
\hline
\end{tabular}


Fig. 5 Geometry of the FE model

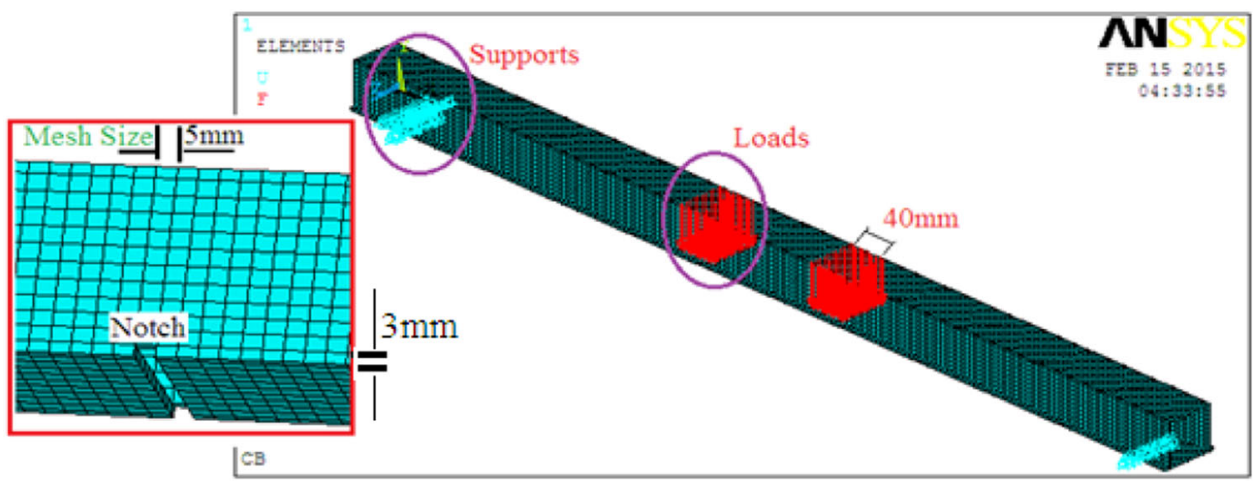

Table 3 Test results

\begin{tabular}{|c|c|c|c|c|c|c|c|c|c|}
\hline \multirow[t]{3}{*}{ Specimens I.D. } & \multicolumn{3}{|c|}{ At the end of linear edge } & \multicolumn{5}{|c|}{ At the peak load } & \multirow[t]{3}{*}{ Failure mode } \\
\hline & \multirow[t]{2}{*}{$\mathrm{P}_{\mathrm{L}}(\mathrm{kN})$} & \multirow{2}{*}{$\begin{array}{l}\mathrm{D}_{1 \mathrm{~L}} \\
(\mathrm{~mm})\end{array}$} & \multirow[t]{2}{*}{$\mathrm{D}_{2 \mathrm{~L}}(\mathrm{~mm})$} & \multirow[t]{2}{*}{$\mathrm{P}_{\mathrm{u}}(\mathrm{kN})$} & \multirow[t]{2}{*}{$\mathrm{D}_{1 \mathrm{u}}(\mathrm{mm})$} & \multirow[t]{2}{*}{$\mathrm{D}_{2 \mathrm{u}}(\mathrm{mm})$} & \multicolumn{2}{|c|}{ Strain $(\mu f)$} & \\
\hline & & & & & & & Com. & Ten. & \\
\hline $\mathrm{CB}$ & 15.3 & 8.25 & 5.62 & 17.8 & 30.15 & 24.42 & 6900 & 5120 & Ductile \\
\hline DB & 8.3 & 4.08 & 3.13 & 11.8 & 16.08 & 11.22 & 800 & 760 & \\
\hline RB1 & 8.3 & 3.77 & 2.7 & 12.3 & 10.89 & 6.88 & 3700 & 1380 & Rupture of the laminates \\
\hline RB2 & 9.3 & 4.19 & 3.61 & 14.5 & 14.59 & 9.21 & 1440 & 1140 & \\
\hline RB3 & 13 & 6.26 & 4.76 & 18.7 & 27.15 & 18.18 & 1720 & 2320 & Debonding \\
\hline RB4 & 8.4 & 4.04 & 3.1 & 14.4 & 24.24 & 12.6 & 1840 & 1520 & Rupture of the laminates \\
\hline RB5 & 12 & 5.32 & 3.81 & 14.6 & 16.67 & 11.42 & 1380 & 1620 & \\
\hline RB6 & 11 & 5 & 3.82 & 17 & 19.3 & 13.25 & 3880 & 4480 & \\
\hline RB7 & 13 & 5.06 & 3.6 & 16.4 & 17.55 & 11.16 & 2360 & 1040 & \\
\hline RB8 & 14 & 6.04 & 4.65 & 22.5 & 32.04 & 23.37 & 12780 & 3240 & \\
\hline RB9 & 14.5 & 8.47 & 5.25 & 19.5 & 24.34 & 18.05 & 6660 & 1680 & Debonding \\
\hline
\end{tabular}

analysis. ANSYS program uses Newton-Raphson method for updating the model stiffness [refer to ANSYS Tavakkolizadeh and Saadatmanesh (2003) and Kadhim Shaat and Fam (2006)]. Finally, initial imperfections or residual stresses caused by the manufacturing process were not included in the modeling.

\section{Results and discussion}

The experimental test results of all the steel beams are summarized in Table 3. In the current section, the effect of cutting the tension flange at mid-span is presented and discussed. Figure 6 shows the load versus deflection at points D1 and D2 from the experimental work and FE simulation of beam $\mathrm{CB}$ and beam DB. Figure 7 shows the load versus longitudinal strains at the measured locations (SA and SB) for the two specimens. The failure mode as observed from the experimental work and as obtained from the numerical analysis for the two beams are showed in Fig. 8. From these figures, it can be concluded that the finite element simulation gives acceptable results in comparison with the experimental results. From Fig. 6, it can be concluded that the relation between experimental load and the deflection at the mid span of beam CB is linear up to $15.3 \mathrm{kN}$ total load and $8.25 \mathrm{~mm}$ corresponding mid-span deflection. After that the plasticity took place and growth in the bottom flange, the top flange and the two webs at the loading positions and their surrounding area, making load-deflection curve nonlinear up to an applied load equals $17.8 \mathrm{kN}$ and the corresponding deflection at mid-span equals $15.5 \mathrm{~mm}$, after that the deflection increased without significant change in the load. Also this figure shows that the strength of beam DB has been severely degraded as a result of notching the lower steel flange at midspan. Table 3 shows $34 \%$ reduction in the ultimate load. Figure 8 shows that the deformed shape at the ultimate load as observed from the experimental work and as obtained from the numerical analysis for beam $\mathrm{CB}$ is ductile failure mode. For the damaged beam, significant yielding was observed and at the end of the test, the measured crack width was $7.2 \mathrm{~mm}$. Figure 9 shows numerical normal stresses distribution for the two beams at the ultimate load. This 
Fig. 6 Load-deflection curves of non-retrofitted specimens; left at point $\mathrm{D} 1$ and right at point D2
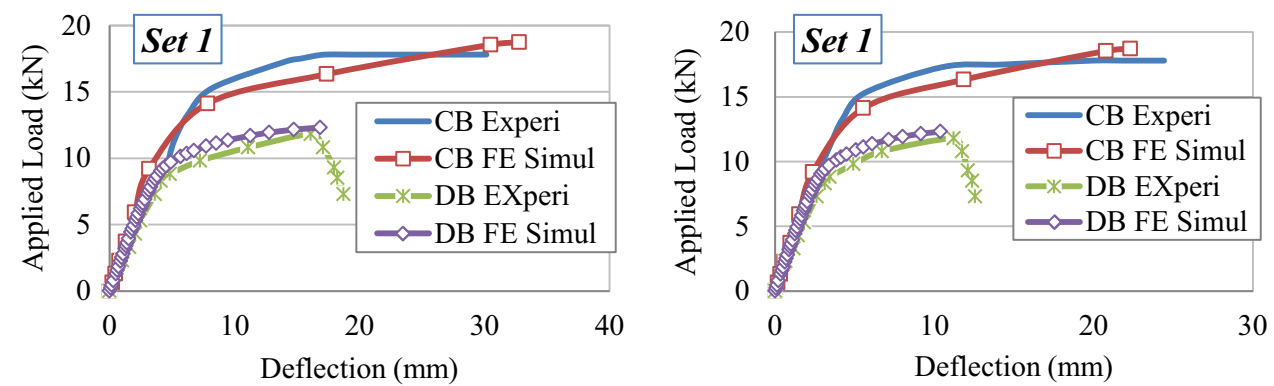

Fig. 7 Experimental and FE simulation total load-strain curves of non-retrofitted specimens
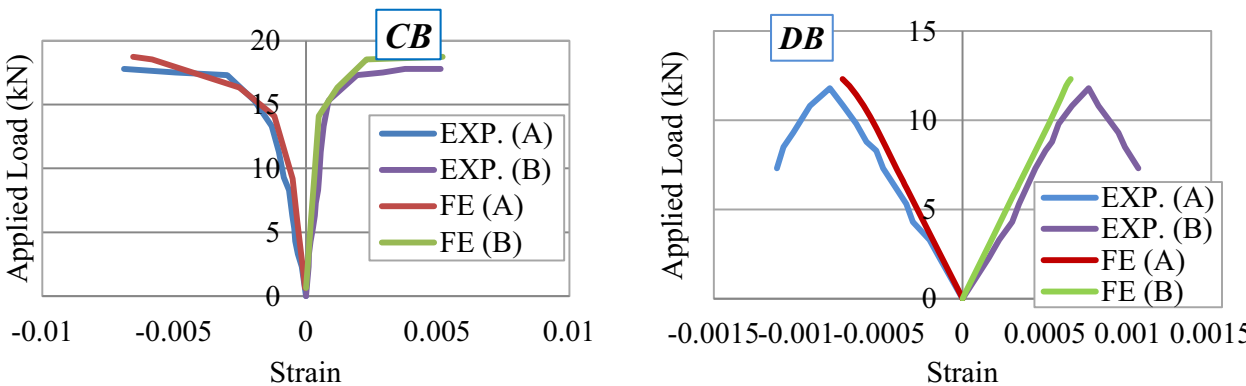
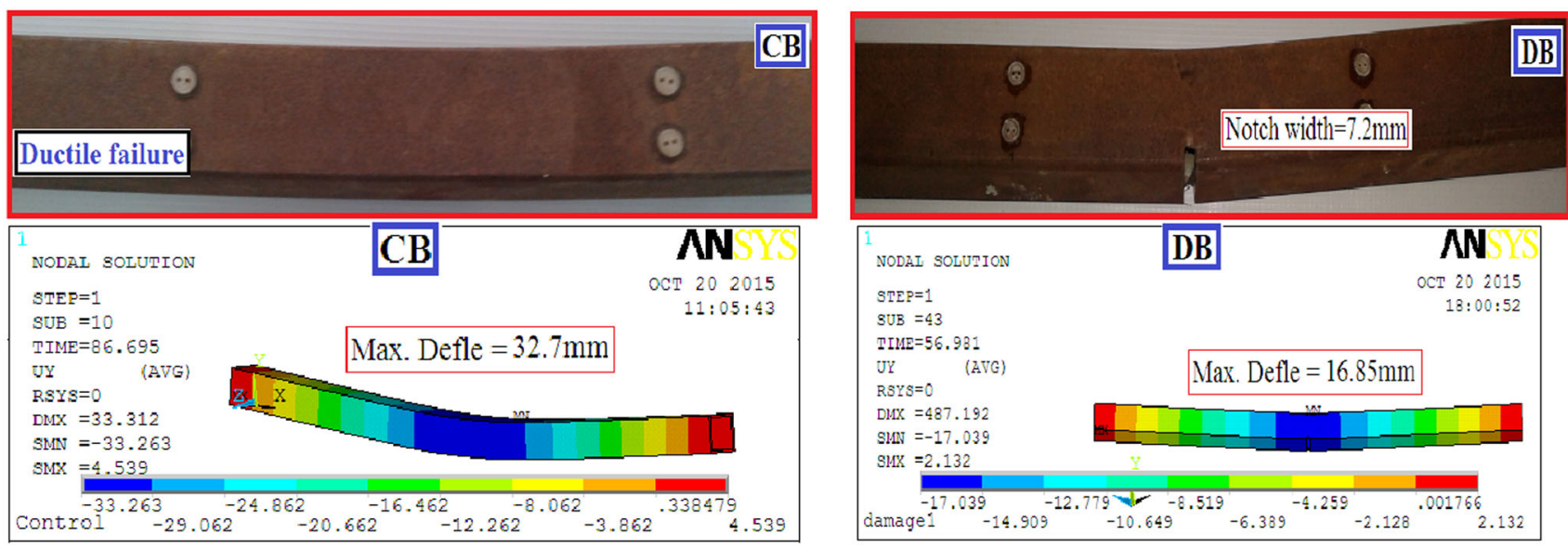

Fig. 8 Failure modes of non-retrofitted specimens
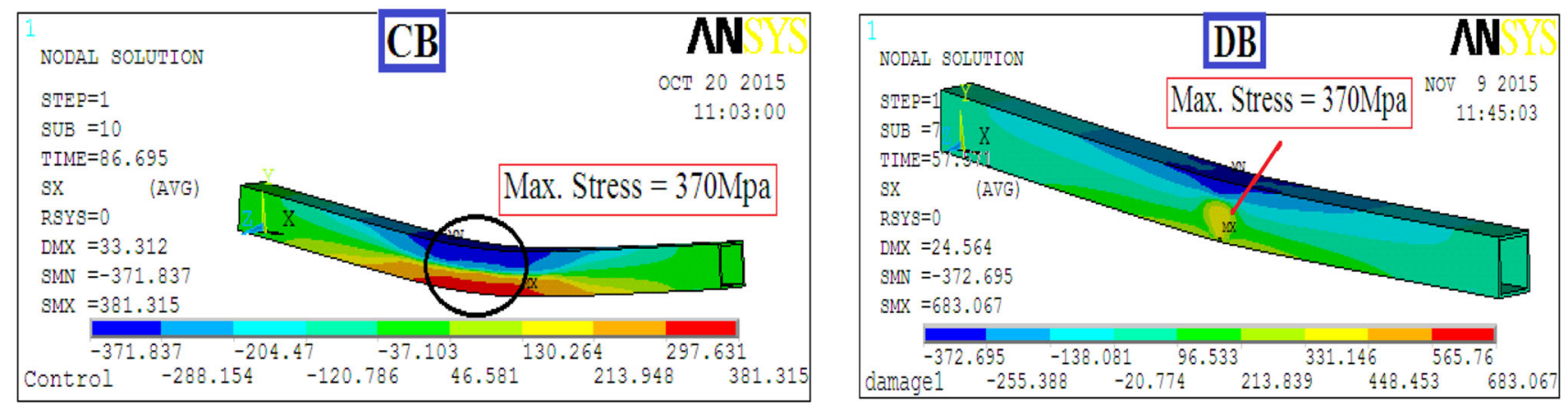

Fig. 9 Numerical normal stresses distribution at the ultimate load of non-retrofitted specimens 
Fig. 10 Load-deflection curves of retrofitted specimens (Set 2); left at D1 and right at D2 point
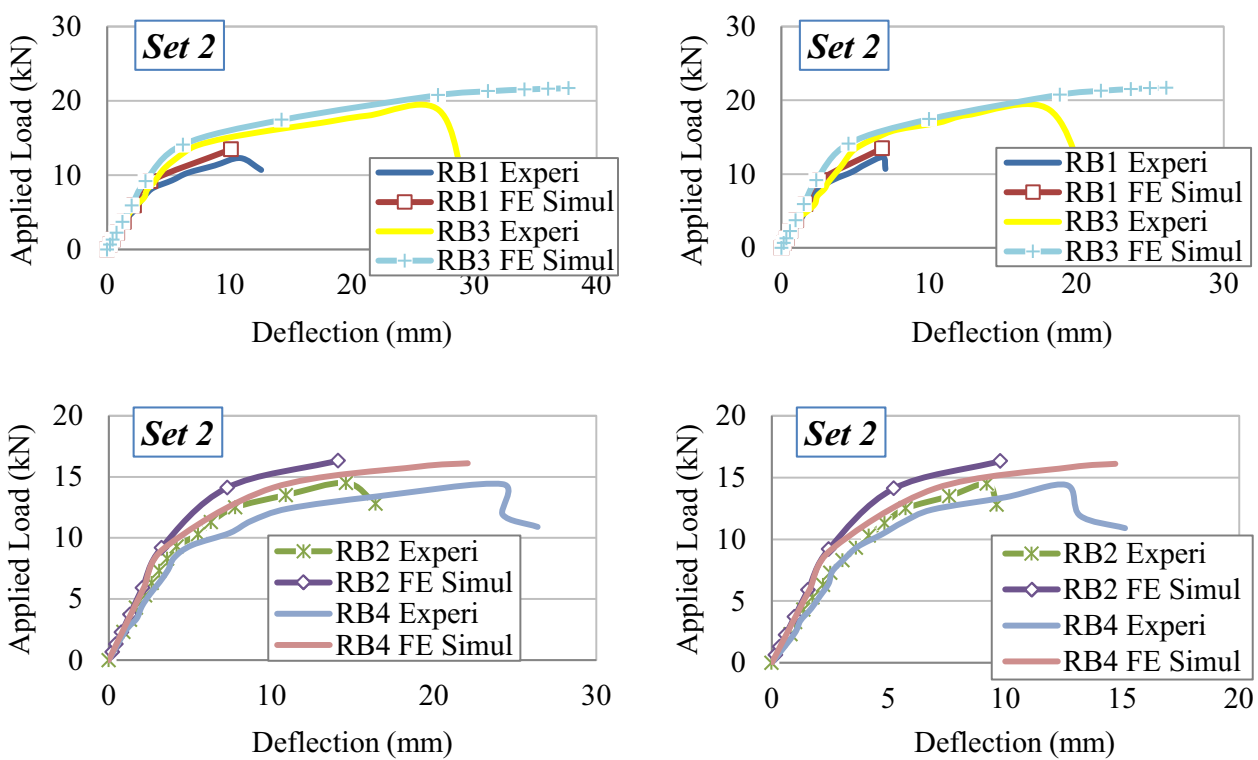

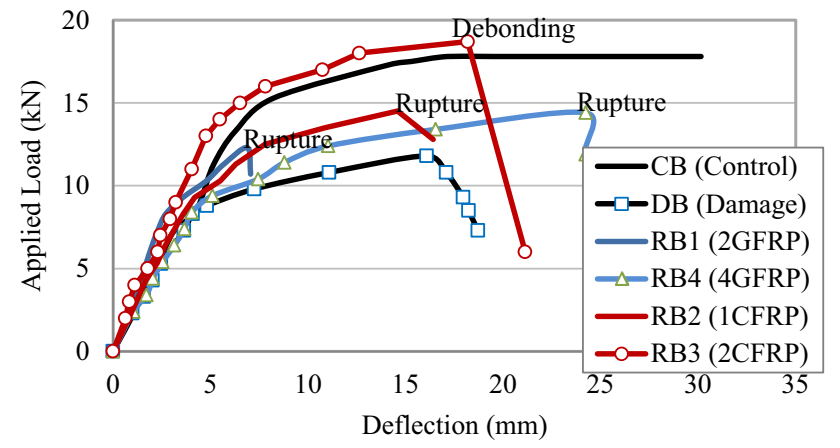

Fig. 11 Experimental total load-deflection curves of retrofitted specimens (Set 2) figure shows that the region around the cut edge (the notch) of the flange in notch damaged beams yields much earlier than farther regions along the web, due to stress concentration.

The results of repaired beams with the composite materials bonded on the lower side of the tension steel flange only (Set 2) in terms of load-deflection curves, loadstrain curves, failure modes and normal stresses distributions are presented in Figs. 10, 11, 12, 13. Figure 10 shows the comparison between the experimental and numerical results in terms of load-deflection curves for retrofitted specimens (Set 2). This figure shows that the numerical and the experimental results are close; the difference between
Fig. 12 Load-strain curves of retrofitted specimens (Set 2); Load-strain curves of retrofitted specimens (Set 2)
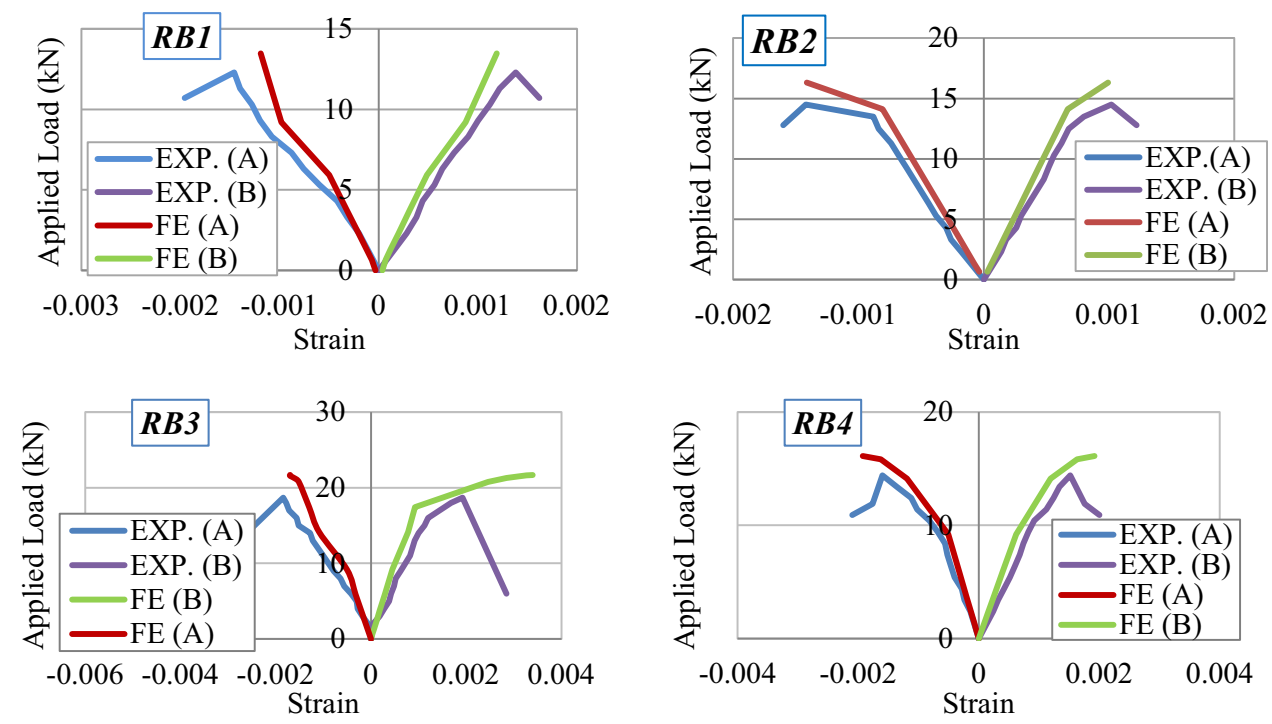

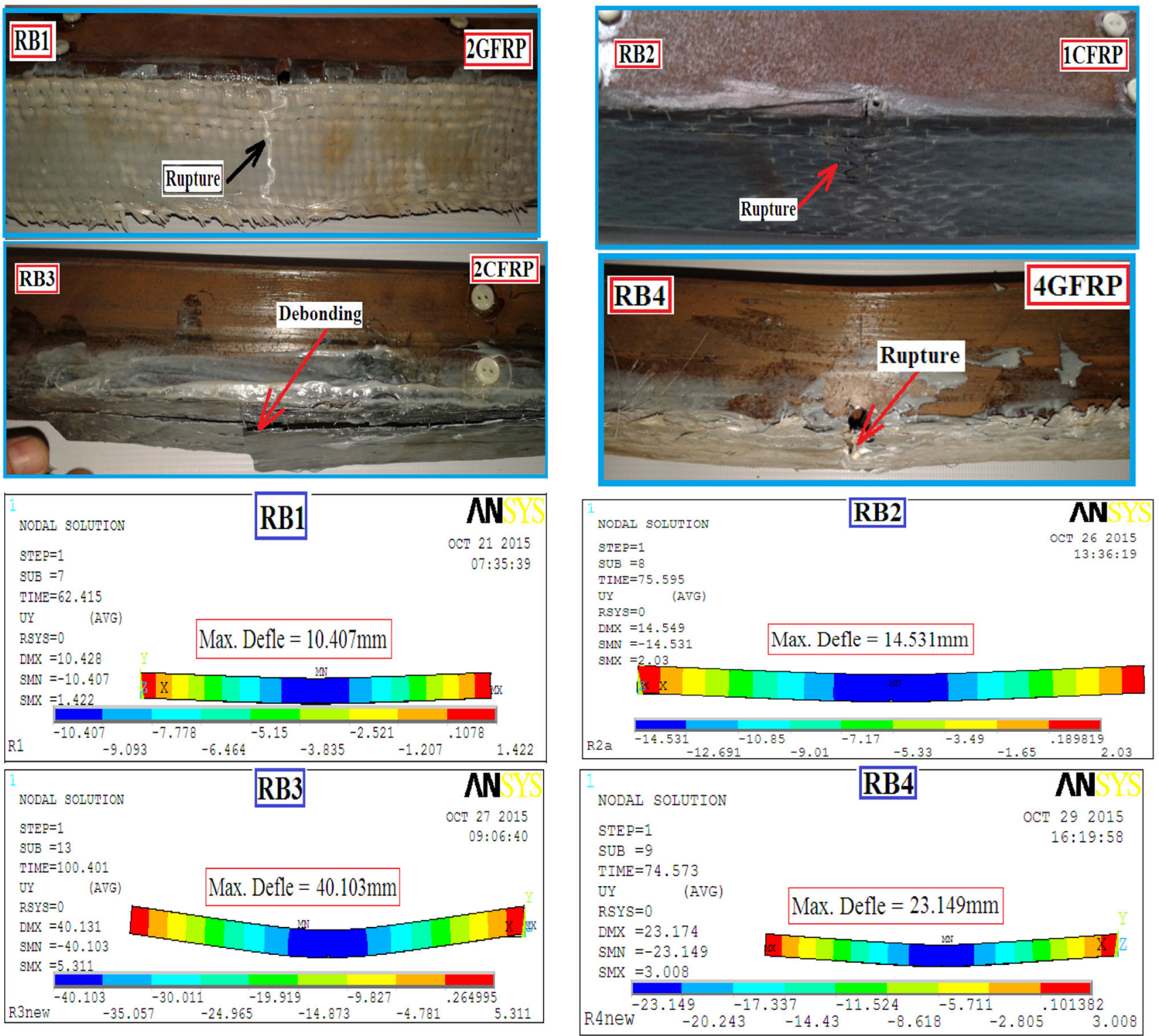

Fig. 13 Failure modes of Set 2 specimens

the results not exceed than $15 \%$. Figure 11 shows the responses of specimens Set 2, compared to beams CB and DB. The figure shows that beam RB3 reached flexural stiffness values higher than the intact beam, which is attributed to the high value of elastic modulus of CFRP. Table 3 shows gains in ultimate load of $5.1 \%$. This beam failed at $17.8 \mathrm{kN}$ ultimate load and 27.15 and $18.18 \mathrm{~mm}$ corresponding deflections at points D1 and D2 due to the occurrence of the debonding CFRP as shown in Fig. 13. Also Fig. 11 indicates that the retrofitted beams (RB1, RB2 and RB4) give higher responses than the notch damaged beam but they not achieve the full stiffness and ductility of beam $\mathrm{CB}$ and their ultimate load was 30.9, 18.54 and

$19.10 \%$ lower than the ultimate load of the intact beam, as indicated in Table 3. Also these results showed that increasing the number of FRP layers increases the ultimate load. Figure 12 shows the load versus strains at two different locations (SA and SB) of Set 2 specimens. From these figures, it can be clearly seen that the numerical model gives a good outcome compared to the experimental tests results. The failure mode of beams RB1, RB2 and RB4 occurred by rupture of the FRP sheets at mid-span, as shown in Fig. 13 due to reaching the maximum strength of FRP (see Fig. 14).

The structural performance of the retrofitted specimens with the composite materials bonded on the lower side of the 

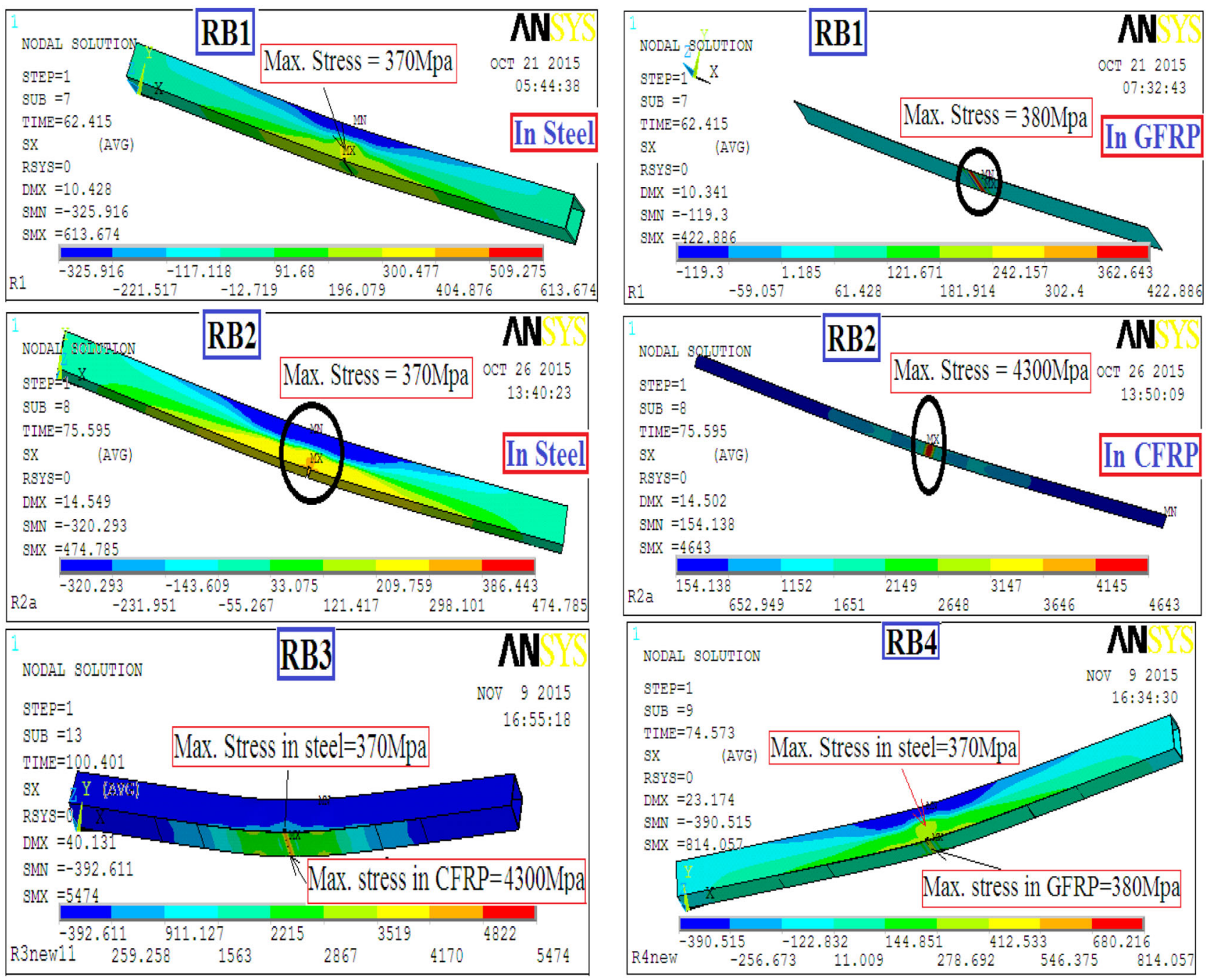

Fig. 14 Numerical normal stresses at the ultimate load of (Set 2) retrofitted specimens

tension steel flange and on a part of the two webs with height $(h)$ (Set 3) are presented and discussed in this section. Figure 15 shows the experimental and numerical loaddeflection curves at points D1 and D2 and Fig. 16 presents the comparison between experimental and numerical results of beams Set 3 in term of load verses strain. These figures showed that the FE simulation gives good results compared to the experimental results. Figure 17 shows the experimental load-deflection curves of specimens Set 3 (RB5, RB6, RB7 and RB8), compared to the reference control intact beam and the damaged beam. This figure and Table 3 indicate that beam RB8 achieves ultimate load values higher than beam CB by about $26.4 \%$. Also beam RB8 has an increase in ductility in comparison with beam CB. This beam failed at $22.5 \mathrm{kN}$ ultimate load and 32.04 and $23.37 \mathrm{~mm}$ corresponding deflections at points D1 and D2 due to the occurrence of the rupture CFRP at the midspan as shown in Fig. 18. The failure mode of all beams Set 3 occurred by rupture of the FRP sheets at mid-span, as shown in Fig. 18. Figure 19 presents the numerical normal stresses of retrofitted beams Set 3.

The results of the specimen RB9 are presented in Figs. 20, 21, 22, 23. This specimen was repaired with two layers of CFRP and four externally bonded GFRP strips. These strips were wrapped around the whole section of the beam at the ends of the CFRP layers. Figure 21 indicates that the repaired specimen RP9 achieves ultimate load value higher than beam CB by about $9.55 \%$. Figure 22 shows that the end debonding is avoid in this beam and the debonding initially appeared at the mid-span. 
Fig. 15 Load-deflection curves of retrofitted specimens (Set \#3); left at D1 and right at D2 point

Fig. 16 Experimental and FE simulation load-strain curves of retrofitted specimens (Set 3)
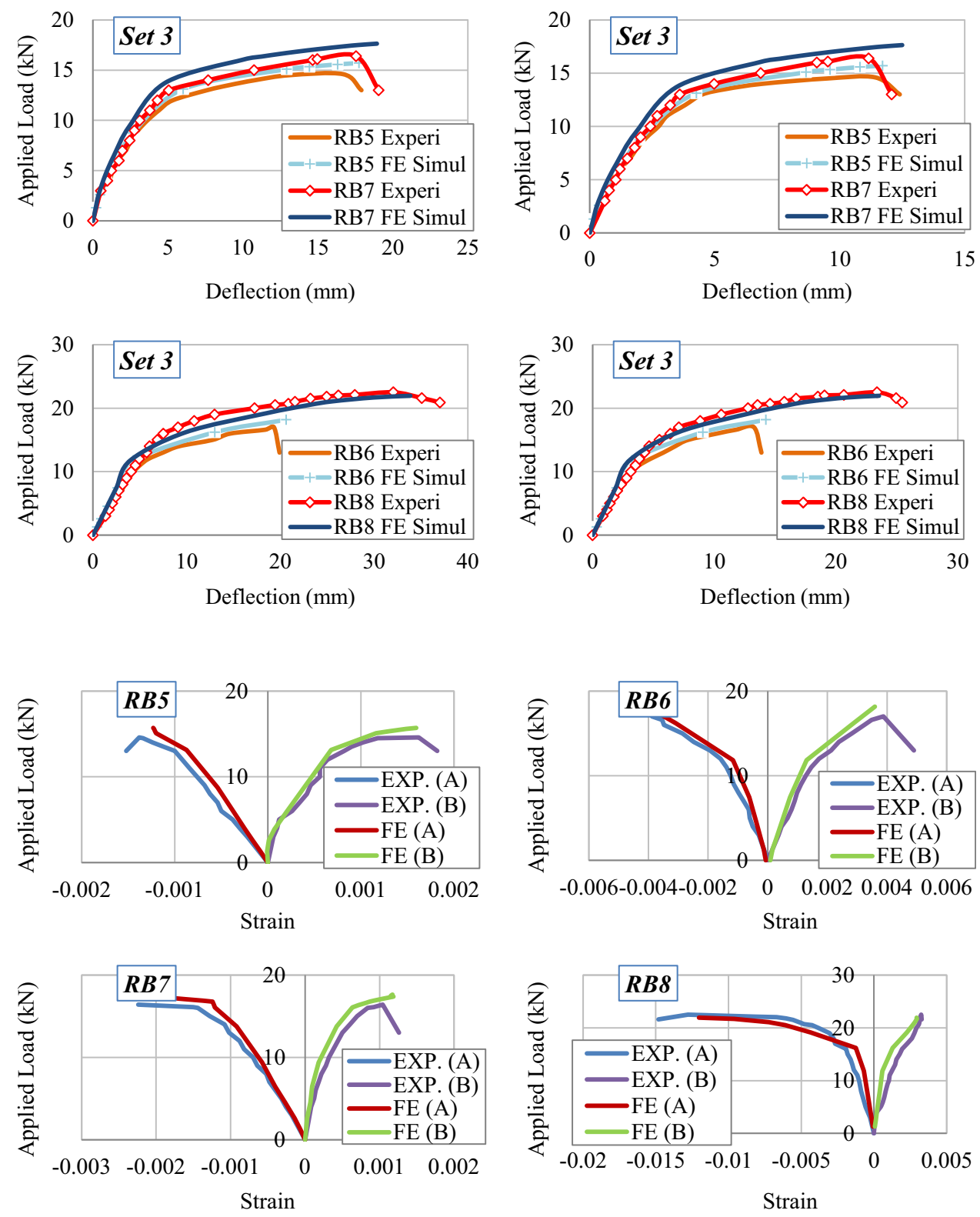

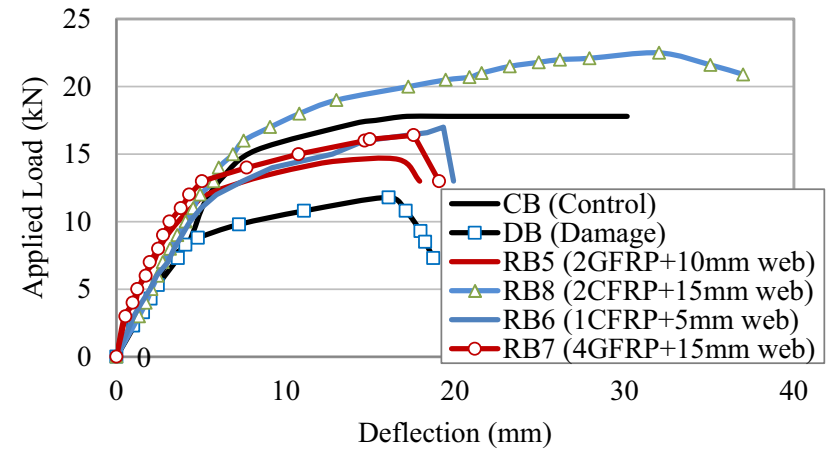

Fig. 17 Experimental total load-deflection curves of retrofitted specimens (Set 3)

\section{Conclusions}

The main goal of this study was to study repairing of damaged box steel beams to recover their original capacities. Experimental and numerical investigations were carried out for testing eleven box steel beams (control intact beam, notch damaged beam and nine retrofitted beams) in two-point bending. The nine beams were artificially damaged and have been repaired using FRP sheets. The parameters considered were the effect of FRP type (GFRP and CFRP), number of layers and the effect of wrapping the composite material to cover a part of the webs. Based on these studies, the following conclusions are drawn: 

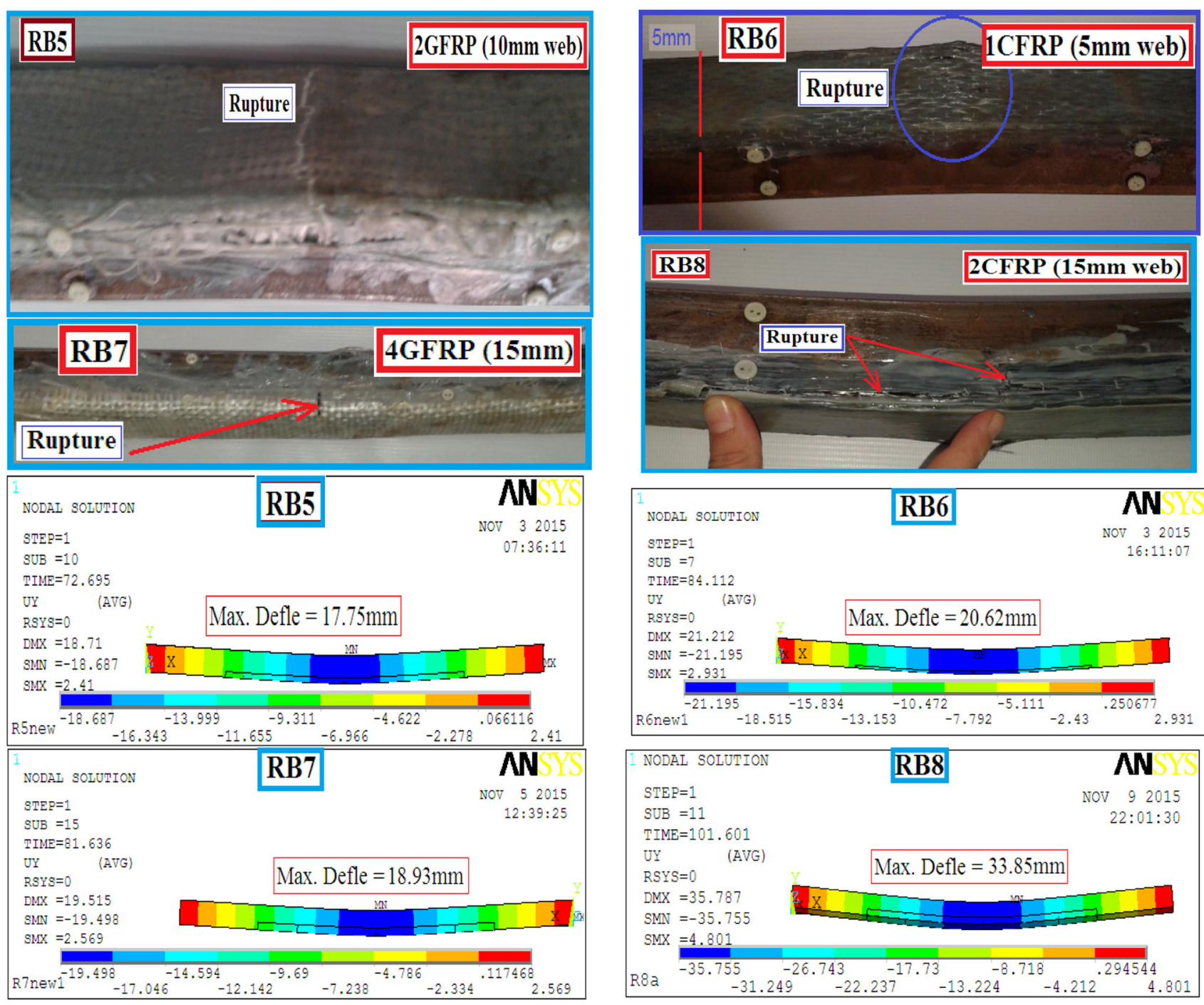

Fig. 18 Failure modes of specimens Set 3

1. The FE simulations give acceptable results in comparison with the experimental results.

2. The flexural strength of beam DB tested has been reduced by $34 \%$ as a result of notching of the tension flange at the mid-span.

3. The failure mode of the intact beam is ductile mode failure. Also the region around the cut edge (the notch) of the flange in notch damaged beam yields earlier than farther regions along the web because of stress concentration.

4. The retrofitted beams with CFRP reached ultimate load values higher than the retrofitted beams with GFRP.

5. RB3 repaired beam reached ultimate load value higher than beam CB (an increase in ultimate load of $5.1 \%$ ). On the other hand specimen RB8 restored the ultimate

strength of beam $\mathrm{CB}$ and even exceeded them by $26.4 \%$ and it has an increase in ductility in comparison with beam CB.

6. The specimen repaired with two layers of CFRP bonded on the lower flange and four GFRP strips wrapped around the whole section of the beam at the ends of the CFRP layers achieves an increase in the ultimate load than beam CB by about $9.55 \%$.

7. The girder repaired using one layer CFRP sheets failed by rupture of the sheets and the beam repaired using two layers CFRP sheets attached with the tension flange only failed by debonding at the end of the sheets. This debonding is hidden by wrapping the sheet on the web in beam RB8 and by wrapping strips of GFRP at the CFRP sheet ends. 


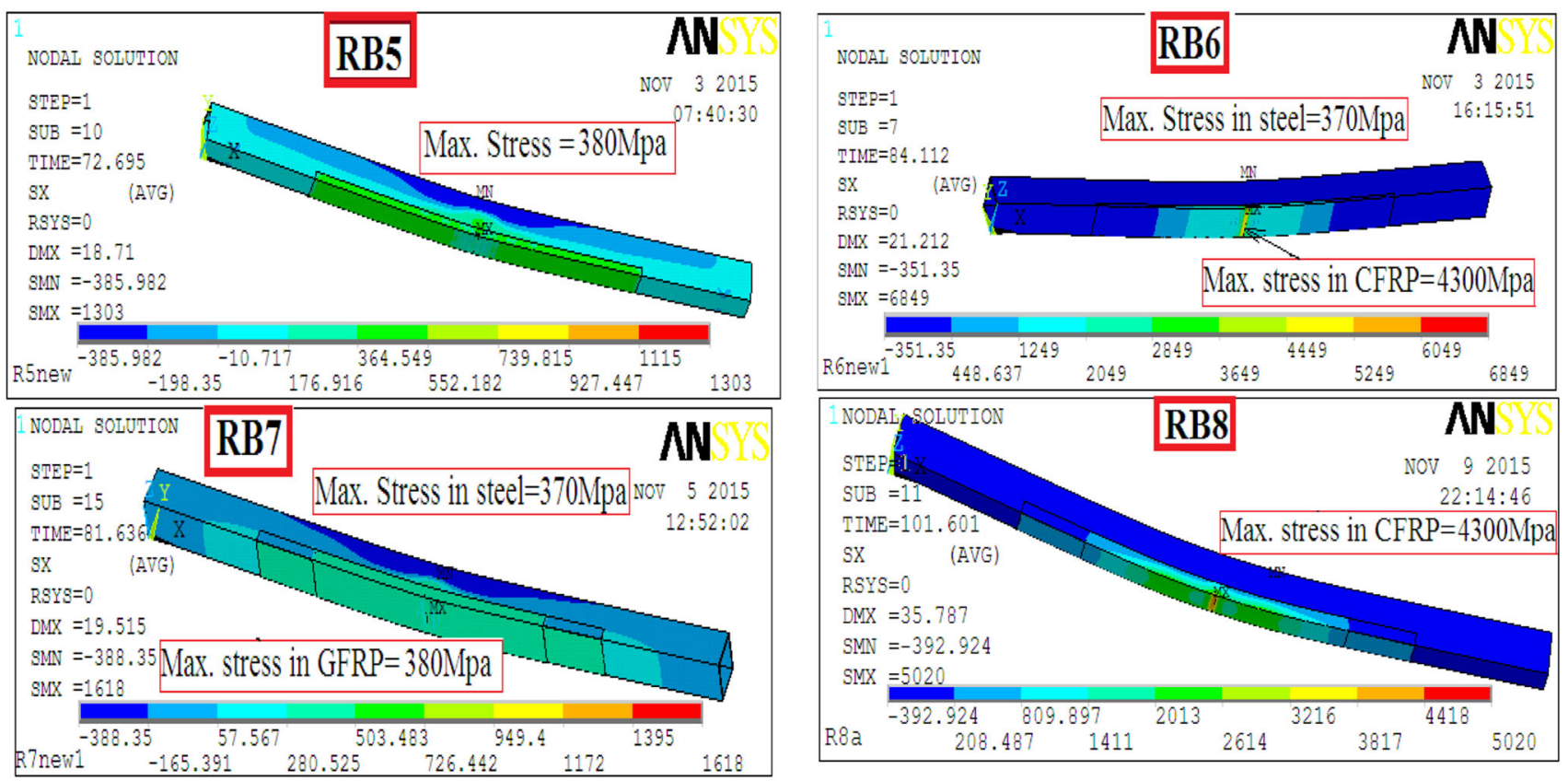

Fig. 19 Numerical normal stresses at the ultimate load of retrofitted specimens Set 3

Fig. 20 Load-deflection curves of retrofitted specimens Set 4
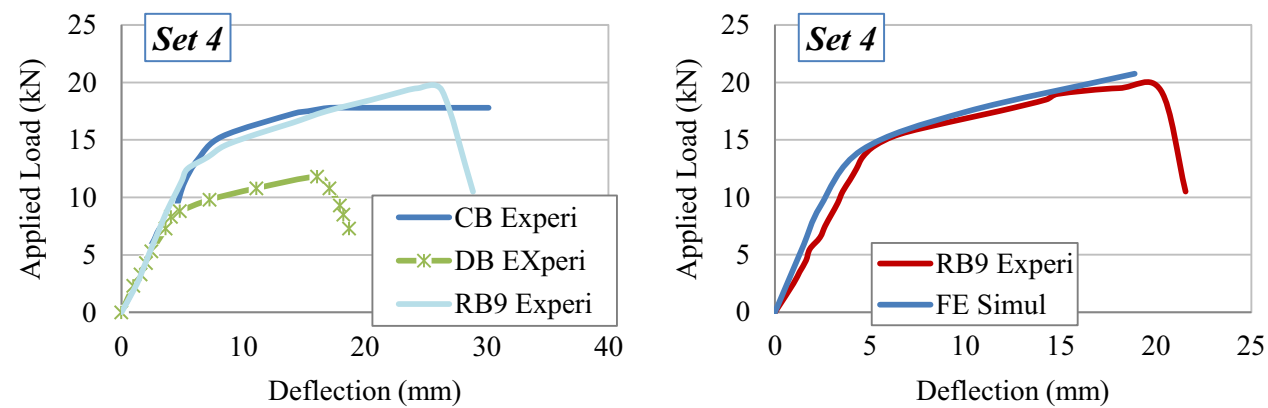
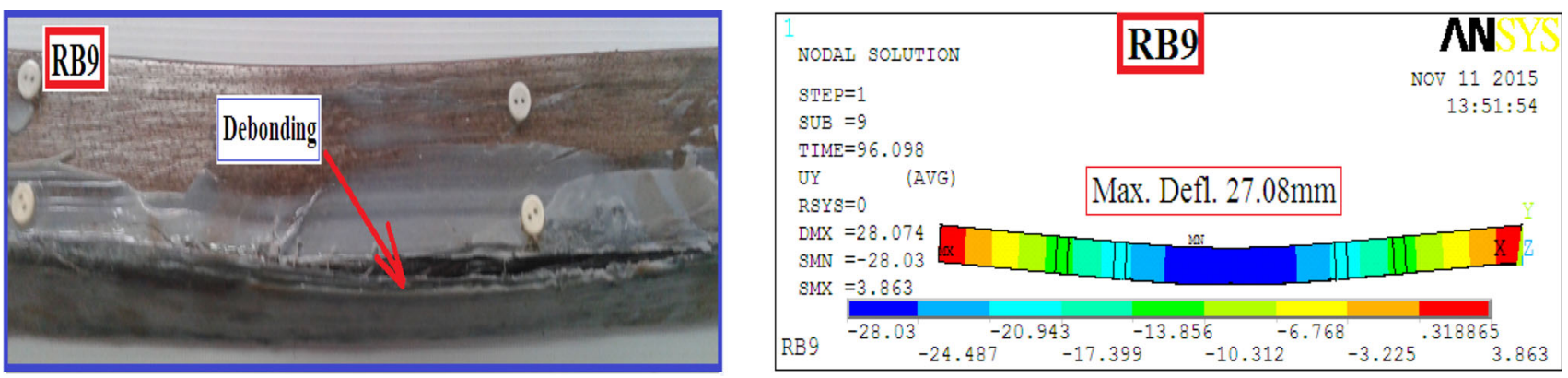

Fig. 21 Failure modes of specimens Set 4 


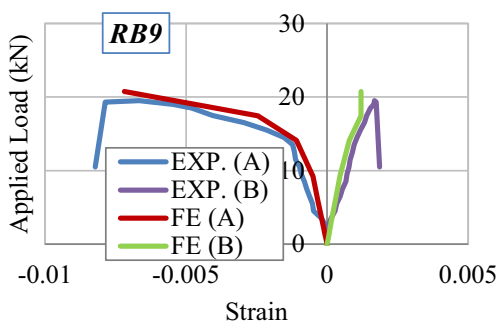

Fig. 22 Load-strain curves of beam RB9

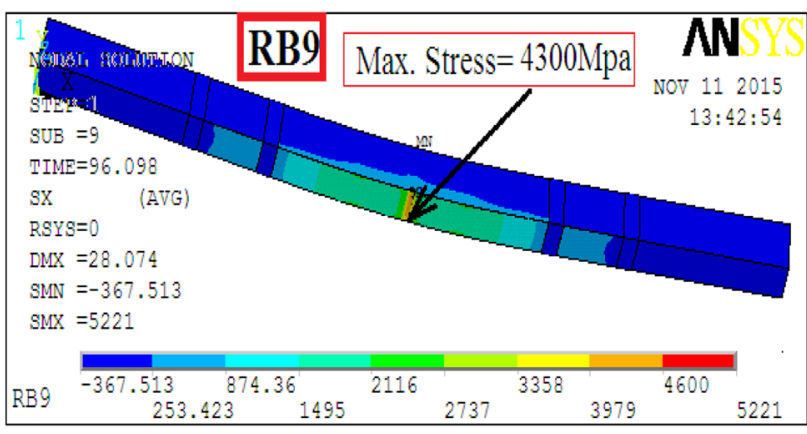

Fig. 23 Normal stresses at the ultimate load of beam RB9

8. Experimental and numerical results indicate the effectiveness of CFRP, as a candidate retrofitting material, for damaged steel structures.

Open Access This article is distributed under the terms of the Creative Commons Attribution 4.0 International License (http://crea tivecommons.org/licenses/by/4.0/), which permits unrestricted use, distribution, and reproduction in any medium, provided you give appropriate credit to the original author(s) and the source, provide a link to the Creative Commons license, and indicate if changes were made.

\section{References}

Al-Saidy AH, Klaiber FW, Wipf TJ (2004) Repair of steel composite beams with carbon fiber-reinforced polymer plates. J Compos Constr ASCE 2(2):163-172

ANSYS (2009) ANSYS Help. Release 12.0, Copyright

Buyukozturk O, Hearing B (1999) Failure behavior of pre-cracked concrete beams retrofitted with FRP. J Compos Constr (ASCE) 3(2):138-144

Gillespie JW, Mertz DR, Edberg WM, Ammar N, Kasai K, Hodgson IC (1996) Rehabilitation of steel bridge girders through application of composite materials. In: 28th International SAMPE Technical Conference. November 4-7, pp 1249-1257

Gu X, Peng B, Chen G, Li X, Ouyang Y (2012a) Rapid strengthening of masonry structures cracked in earthquakes using fiber composite materials. J Compos Constr (ASCE) 5(16):590-603
Hmidan A, Kim Y, Yazdani S (2013) Crack-dependent response of steel elements strengthened with cfrp sheets. Constr Build Mater 49:110-120

Jesus AMP, Pinto JMT, Morais JJL (2012) Analysis of solid wood beams strengthened with cfrp laminates of distinct lengths. Constr Build Mater 35:817-828

Kadhim M (2012) Effect of CFRP Plate length strengthening continuous steel beam. J Constr Build Mater 28:648-652

Kalavagunta S, Naganathan S, Mustapha K (2014) Axially loaded steel columns strengthened with CFRP. Jordan J Civil Eng 8(1):58-69

Liu X, Silva PF, Nanni A (2001) Rehabilitation of steel bridge members with FRP composite materials. In: Proceedings of the international conference on composites in construction, October 10-12, Porto, Portugal, pp 613-617

Michael J, Chajes MJ, Chacon AP, Swinehart MW, Richardson D, Wenczel R, Liu W (2005) Applications of advanced composites to steel bridges. Technical Report, Delaware Center for Transportation, University of Delaware, Newark

Narmashiri K, Jumaat MZ (2011) Reinforced Steel I-Beams: a Comparison between 2D and 3D simulation. J Sim Model Pract Theory 19:564-585

Ochi N, Matsumura M, Hisabe N (2011) Experimental study on strengthening effect of high modulus cfrp strips with different adhesive length installed onto the lower flange plate of $i$ shaped steel girder. J Proc Eng 14:506-512

Photiou NK, Hollaway LC, Chryssanthopoulos MK (2006a) Strengthening of an artificial degraded steel beam utilizing a carbon/glass composite system. Constr Build Mater 20(1-2):11-21

Photiou NK, Hollaway LC, Chryssanthopoulos MK (2006b) Selection of Carbon-Fiber-Reinforced Polymer Systems for Steelwork Upgrading. J Mater Civ Eng ASCE 5(18):641-649

Salama T, Abd-El-Meguid A (2010) Strengthening steel bridge girders using CFRP. Technical Report, University Transportation Center for Alabama (UTCA), The University of Alabama, Birmingham, No. 06217, pp 1-184

Schnerch D, Dawood M, Rizkalla S, Sumner E (2007) Proposed design guidelines for strengthening of steel bridges with FRP materials. Constr Build Mater 2:1001-1010

Shaat A (2007) Structural behavior of steel columns and steelconcrete composite girders retrofitted using CFRP. Ph. D, Thesis, Queen's University, Kingston, Ontario

Shaat A, Fam A (2006) Axial loading tests on short and long hollow structural steel columns retrofitted using carbon fibre reinforced polymers. Can J Civ Eng 4(33):458-470

Shaat A, Fam A (2009) Slender steel columns strengthened using high- modulus cfrp plates for buckling control. J Compos Constr (ASCE) 1(13):2-12

Tavakkolizadeh M, Saadatmanesh H (2003a) Strengthening of steelconcrete composite girders using carbon fiber reinforced polymers sheets. J Struct Eng (ASCE) 1(129):30-40

Tavakkolizadeh M, Saadatmanesh H (2003b) Repair of damaged steel-concrete composite girders using carbon fiber reinforced polymers sheets. J Compos Constr ASCE 4(7):311-322

Teng JG, Yu T, Fernando D (2012) Strengthening of steel structures with fiber-reinforced polymer composites. J Construct Steel Res 78:131-143

Yu Y, Chiew SP, Lee CK (2011) Bond failure of steel beams strengthened with FRP laminates-part 2: verification. J Compos Part B 42:1122-1134 